\title{
Response of the human oesophagus to d-tubocurarine and atropine
}

\author{
P. A. KANTROWITZ, C. I. SiEgel, M. J. STRONG, AND T. R. HENDRIX \\ From the US Army Chemical Research and Development Laboratories, Army Chemical Center, \\ Maryland, and the Johns Hopkins University School of Medicine, Baltimore, USA
}

SUMMARY Intraluminal manometric studies of normal swallowing activity fail to distinguish between the peristaltic response of striated and smooth muscle. Studies were performed to determine if the two types of musculature differ in their response to pharmacological stimulation. After the administration of d-tubocurarine, peristaltic amplitude in the striated muscle segment decreased by 26 to $51 \%$, while amplitude in the smooth muscle portion was not significantly affected. The administration of atropine, on the other hand, abolished or diminished smooth muscle peristalsis without altering striated muscle activity. The injection of neostigmine restored peristaltic amplitude toward normal in both striated and smooth muscle portions. These studies demonstrate that although the striated and smooth muscle segments are indistinguishable during normal oesophageal peristalsis, they do differ markedly in their pharmacological response. Pharmacologically, oesophageal striated muscle responds like other striated muscle and oesophageal smooth muscle responds like smooth muscle elsewhere.

Peristalsis normally progresses continuously through the upper striated and lower smooth muscle segments of the human oesophagus (Ingelfinger, 1958). Moreover, the two types of oesophageal musculature cannot be distinguished by studying normal swallowing. Intraoesophageal manometric studies have therefore been performed to determine if the striated and smooth muscle segments differ in their response to pharmacological stimulation. The pharmacological agents employed were d-tubocurarine and atropine. In conventional dosages, d-tubocurarine selectively inhibits striated muscle while atropine affects only smooth muscle (Goodman and Gilman, 1965). The present report describes the oesophageal response of normal subjects to these pharmacological agents.

\section{Material and Methods}

A standard technique for determining intraluminal pressures was employed. Three opentipped polyvinyl catheters (internal diameter $1.4 \mathrm{~mm}$ ), with the tips fixed in position $5 \mathrm{~cm}$ apart, were passed nasogastrically in fasted subjects. With the subjects supine, the waterfilled catheters were connected to Sanborn differential pressure transducers. The zero lines of the transducers were positioned at the approximate level of the oesophagus. The transducers were connected to a Sanborn multichannel, direct-writing recorder, and simultaneous pressure measurements were obtained from three points in the oesophagus. Pneumographs around the abdomen and neck were connected to a 
fourth channel and permitted concomitant monitoring of respiratory excursions and swallowing. An intravenous infusion of $5 \%$ dextrose in water was begun in an antecubital vein.

Six healthy males, ranging from 19 to 26 years of age, served as subjects in this investigation. In each subject, the catheters were withdrawn through the oesophagus until the most proximal tip entered the upper oesophageal sphincter. The catheters were then reinserted 1 to $2 \mathrm{~cm}$, flushed with water, and taped in position. In this manner, the levels of the catheter tips were maintained at 1 to 2,6 to 7 , and 11 to $12 \mathrm{~cm}$ below the upper oesophageal sphincter. The oesophageal motor response to a swallow of either a sip of water or of saliva was recorded from 14 to 46 times (Table I).

After each control study, an initial dose of 3.0 or $4.5 \mathrm{mg}$ d-tubocurarine chloride was injected rapidly through the infusion tubing. The subject continued to swallow either water or saliva on direction, and a continuous recording was obtained. One and a half milligram increments of d-tubocurarine chloride were administered at intervals of three to five minutes. Muscular strength was assessed by serially eliciting maximal hand grip and voluntary elevation of the head. In all subjects, the last dose of tubocurarine was administered nine to 16 minutes after the initial dose. Each subject received a total of 9.0 or $10.5 \mathrm{mg}$ tubocurarine.

Two to nine minutes after the last dose of tubocurarine (11 to 23 minutes after the initial tubocurarine injection), $1.0 \mathrm{mg}$ of atropine sulphate was administered through the intravenous tubing. The subject continued to swallow on direction. One to four minutes after atropine administration, $1.5 \mathrm{mg}$ neostigmine methylsulphate was injected into the infusion tubing. Additional swallows were recorded during the ensuing 10 to 15 minutes.

The peak amplitude of the peristaltic wave (less the mean resting pressure) was determined for each swallowing complex. Mean peak peristaltic pressure was calculated by averaging all peristaltic amplitudes recorded at each level.

Data were obtained from the three recording tips; values from the middle tip were in all instances intermediate. Therefore, to demonstrate the relative effects of the pharmacological agents on striated and smooth muscle, only the data obtained from the proximal (striated muscle) and distal (smooth muscle) sites are presented.

\section{Results}

Manometric data were obtained from each subject during a control period and after the administration of d-tubocurarine chloride. In five of the six subjects, data were also obtained following sequential administration of atropine sulphate and neostigmine methylsulphate. The remaining subject (B.Z.) vomited abruptly after the administration of atropine, probably due to the large number of swallows of water he had taken during the control period, and thus in this subject no data for neostigmine effect are available.

Table I shows the control and pharmacological data for the six subjects. In the striated muscle portion of the oesophagus (proximal recording site), mean peristaltic pressure in the six subjects during the control period was $34.5 \mathrm{~mm} \mathrm{Hg}$ (range 27.9 to $38.7 \mathrm{~mm} \mathrm{Hg}$ ). The administration of d-tubocurarine chloride resulted in a diminution of mean peristaltic pressures to $20.6 \mathrm{~mm} \mathrm{Hg}$ (range 19.1 to $25.4 \mathrm{~mm} \mathrm{Hg}$ ). This represented a decrease of $39.6 \%$ from the control value. Following the injection of atropine, mean peristaltic amplitude in the six subjects was $21.6 \mathrm{~mm} \mathrm{Hg}$ (range 18.0 to $30.3 \mathrm{~mm} \mathrm{Hg}$ ); this represented no consistent change from the effect

\begin{tabular}{|c|c|c|c|c|c|c|c|c|c|}
\hline \multirow[b]{2}{*}{ Subject } & \multirow[b]{2}{*}{$\begin{array}{l}\text { Segment } \\
\text { Studied }\end{array}$} & \multicolumn{2}{|l|}{ Control } & \multicolumn{2}{|l|}{ Curare } & \multicolumn{2}{|l|}{ Atropine } & \multicolumn{2}{|c|}{ Neostigmine } \\
\hline & & $\begin{array}{l}\text { No. of } \\
\text { Swallows }\end{array}$ & $\begin{array}{l}\text { Mean } \\
\text { Amplitude } \\
\text { (mm Hg) }\end{array}$ & $\begin{array}{l}\text { No. of } \\
\text { Swallows }\end{array}$ & $\begin{array}{l}\text { Mean } \\
\text { Amplitude } \\
(\mathrm{mm} \mathrm{Hg})\end{array}$ & $\begin{array}{l}\text { No. of } \\
\text { Swallows }\end{array}$ & $\begin{array}{l}\text { Mean } \\
\text { Amplitude } \\
\text { (mm Hg) }\end{array}$ & $\begin{array}{l}\text { No. of } \\
\text { Swallows }\end{array}$ & $\begin{array}{l}\text { Mean } \\
\text { Amplitude } \\
\text { (mm Hg) }\end{array}$ \\
\hline \multirow[t]{2}{*}{1} & Upper & 20 & $36 \cdot 5$ & 13 & $20 \cdot 2$ & 11 & 18.4 & 10 & $32 \cdot 0$ \\
\hline & Lower & 20 & $43 \cdot 5$ & 13 & $44 \cdot 7$ & 11 & $0^{1}$ & 10 & $24 \cdot 7$ \\
\hline \multirow[t]{2}{*}{2} & Upper & 19 & $30 \cdot 2$ & 21 & $19 \cdot 1$ & 7 & $18 \cdot 0$ & 15 & $27 \cdot 1$ \\
\hline & Lower & 19 & $30 \cdot 2$ & 21 & $30 \cdot 2$ & 7 & $0^{1}$ & 8 & $25 \cdot 9$ \\
\hline \multirow[t]{2}{*}{3} & Upper & 29 & $36 \cdot 8$ & 20 & $20 \cdot 0$ & 8 & $19 \cdot 1$ & 14 & $34 \cdot 8$ \\
\hline & Lower & 29 & $33 \cdot 9$ & 20 & $36 \cdot 5$ & 8 & $10 \cdot 1$ & 14 & $26 \cdot 4$ \\
\hline \multirow[t]{2}{*}{4} & Upper & 46 & $38 \cdot 7$ & 14 & $19 \cdot 1$ & 5 & $25 \cdot 2$ & & \\
\hline & Lower & 46 & $57 \cdot 5$ & 14 & $51 \cdot 8$ & 5 & $29 \cdot 1$ & & \\
\hline \multirow[t]{2}{*}{5} & Upper & 14 & $36 \cdot 8$ & 13 & $25 \cdot 4$ & 4 & $30 \cdot 3$ & 9 & $32 \cdot 4$ \\
\hline & Lower & 14 & $25 \cdot 7$ & 13 & $26 \cdot 4$ & 4 & $0^{1}$ & 9 & $29 \cdot 7$ \\
\hline \multirow[t]{2}{*}{6} & Upper & 19 & $27 \cdot 9$ & 19 & $19 \cdot 8$ & 5 & $18 \cdot 4$ & 13 & $27 \cdot 2$ \\
\hline & Lower & 19 & $32 \cdot 1$ & 13 & $27 \cdot 9$ & 5 & $0^{2}$ & 12 & $16 \cdot 8$ \\
\hline Mean & $\begin{array}{l}\text { Upper } \\
\text { Lower }\end{array}$ & & $\begin{array}{l}34 \cdot 5 \\
37 \cdot 2\end{array}$ & & $\begin{array}{l}20 \cdot 6 \\
36 \cdot 3\end{array}$ & & $\begin{array}{r}21.6 \\
6.5\end{array}$ & & $\begin{array}{l}30 \cdot 7 \\
24 \cdot 7\end{array}$ \\
\hline
\end{tabular}




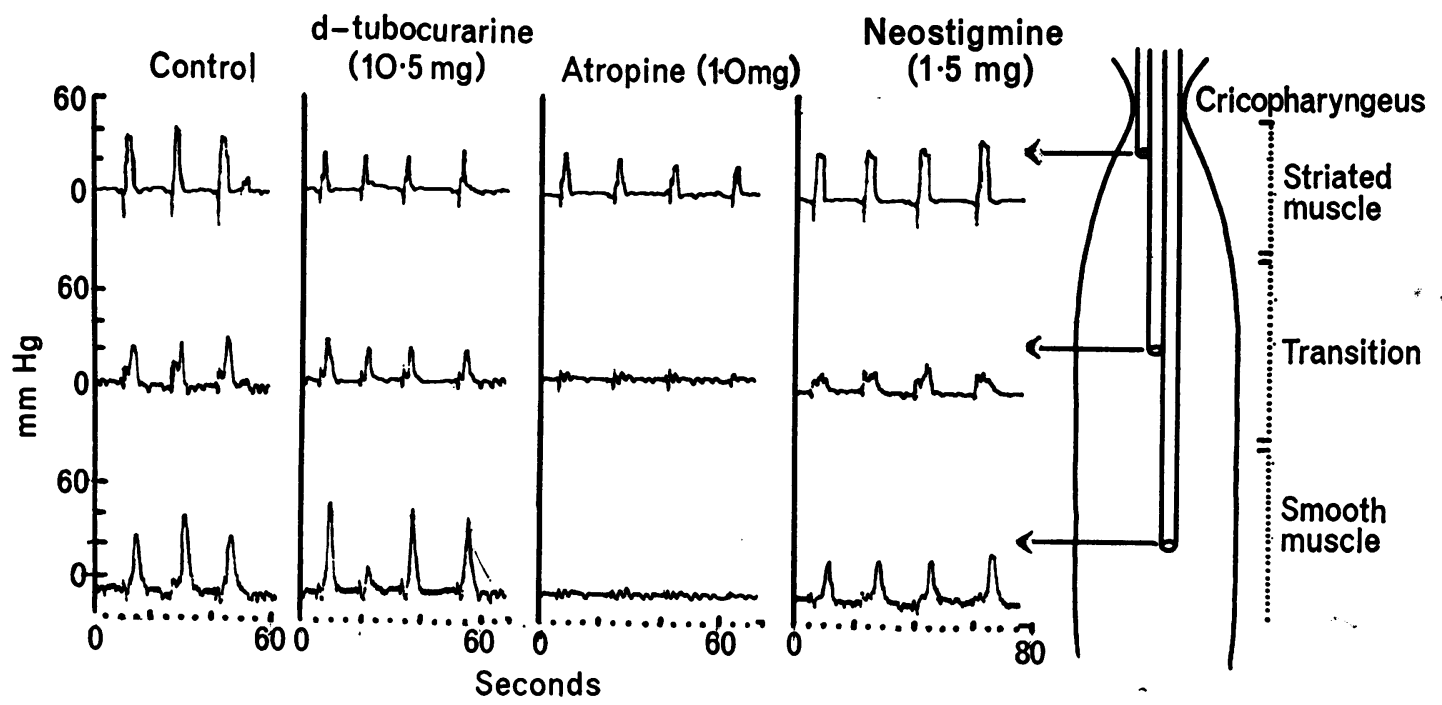

Fig. 1 Portions of manometric recordings obtained during control period and after the administration of d-tubocurarine, atropine, and neostigmine (subject no. 6).
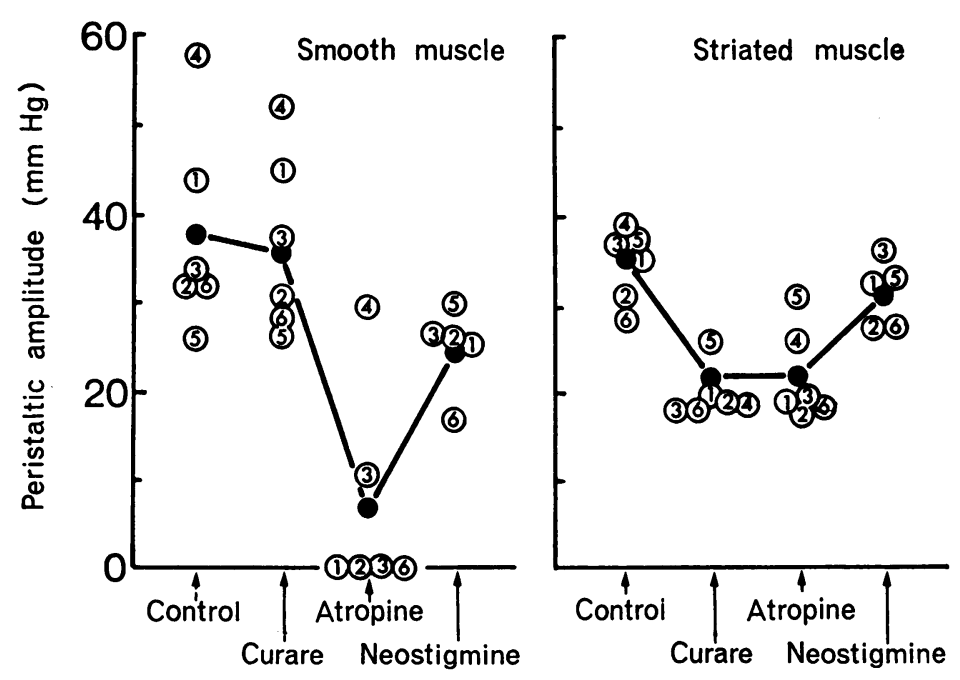

Fig. 2 Mean volumes obtained for upper recording site (labelled striated muscle) and lower recording site (labelled smooth muscle). The mean of values obtained for a given subject is indicated by a numbered circle. The mean for all subjects for each recording period is indicated by a black circle. of tubocurarine alone. In five subjects, after the injection of $1.5 \mathrm{mg}$ neostigmine methylsulphate, mean peristaltic amplitude increased to $30.7 \mathrm{~mm}$ $\mathrm{Hg}$ (range 27.1 to $34.8 \mathrm{~mm} \mathrm{Hg}$ ).

In the smooth muscle portion of the oesophagus (distal recording site), mean peristaltic pressure during the control period was $37.2 \mathrm{~mm}$ $\mathrm{Hg}$ (range 25.7 to $57.5 \mathrm{~mm} \mathrm{Hg}$ ). After the administration of d-tubocurarine chloride, mean peristaltic amplitude was $36.3 \mathrm{~mm} \mathrm{Hg}$ (range 26.4 to $51.8 \mathrm{~mm} \mathrm{Hg}$ ). This average decrease did not represent a significant change from the control period. The administration of atropine markedly diminished peristaltic amplitude or abolished peristaltic activity in all subjects (Table I). The injection of neostigmine methylsulphate resulted in a restoration of peristaltic activity, with a rise in mean peristaltic amplitude to $24.7 \mathrm{~mm} \mathrm{Hg}$ (range 16.8 to $29.7 \mathrm{~mm} \mathrm{Hg}$ ).

During the six control studies, all but two of 149 swallows were followed by peristaltic contraction. With maximal tubocurarine effect, eight of 102 swallows failed to initiate peristalsis.

\section{Discussion}

Anatomical studies have demonstrated that the upper 6 to $8 \mathrm{~cm}$ of the inner muscle layer of the 
human oesophagus is composed entirely of striated muscle (Welcker and Schweigger-Seidel, 1861). Yet, physiologically, this striated muscle segment behaves like the remainder of the oesophagus. In the present study, the pharmacological response of striated and smooth muscle segments of oesophagus was investigated, employing d-tubocurarine, atropine, and neostigmine.

d-Tubocurarine competes with acetylcholine for the receptor sites of striated muscle motor end plates. Reversible combination with these sites raises the threshold to acetylcholine and exerts a paralytic effect. d-Tubocurarine does not compete with acetylcholine at smooth muscle receptor sites (Goodman and Gilman, 1965). In the present study, administration of d-tubocurarine decreased intraluminal peristaltic pressures in the striated muscle segments in all six subjects but peristaltic amplitudes were not altered in the smooth muscle segment. Thus, the same peristaltic wave which developed reduced intraluminal pressure in the striated muscle segment produced normal pressures when it subsequently progressed into the smooth muscle portion of the oesophagus.

Atropine combines reversibly with receptor sites which are innervated by post-ganglionic cholinergic nerves, but it does not compete with acetylcholine released at the striated muscle motor end plates. In this manner, atropine raises the threshold of the smooth muscle cells to acetylcholine and exerts its paralytic effect (Goodman and Gilman, 1965). After the administration of atropine, peristalsis was abolished in four subjects and markedly diminished in the other two subjects at the lower smooth muscle recording site, even though the peristaltic wave had progressed normally through the more proximal striated muscle segment.

Neostigmine, a potent anticholinesterase, is believed to counteract the effect of tubocurarine on striated muscle by depressing cholinesterase activity at the myoneural junction. As a result, acetylcholine accumulates at the muscle's end plate and can more successfully compete with tubocurarine for the receptor sites (Goodman and Gilman, 1965). In addition, a direct effect on striated muscle, independent of anticholinesterase activity, has been ascribed to neostigmine (Riker and Wescoe, 1946). Neostigmine similarly counteracts the effects of atropine on smooth muscle by depressing cholinesterase activity and promoting accumulation of acetylcholine at receptor sites. In the present study, peristaltic pressures in both the striated and smooth muscle portions of the oesophagus returned toward control levels after the intravenous administration of neostigmine.

This study demonstrates that although the striated and smooth muscle of the human oesophagus function indistinguishably in normal peristalsis, they can be clearly differentiated by appropriate pharmacological agents.

\section{References}

Goodman, L. S., and Gilman, A. (1965). The Pharmacological Basis of Therapeutics, 3rd ed., pp. 441-461, 596-611. Macmillan, New York.

Ingelfinger, F. J. (1958). Esophageal motility. Physiol. Rev., 38, 533-584.

Riker, W. F., Jr., and Wescoe, W. C. (1946). The direct action of prostigmine on skeletal muscle; its relationship to the choline esters. J. Pharmacol. exp. Ther., 88, 58-66.

Welcker, H., and Schweigger-Seidel (1861). Verbreitungsgrenzen der quergestreiften und glatten Muskulatur im menschlichen Schlunde. Virchows Arch. path. Anat., 21, 455456. 